\title{
Influence of radical photoinitiators on features of polyacrylate syrups and self-adhesives*)
}

\author{
Konrad Gziut ${ }^{1)}$, Agnieszka Kowalczyk ${ }^{1), * *)}$ \\ DOI: dx.doi.org/10.14314/polimery.2020.4.2
}

\begin{abstract}
Pressure-sensitive adhesives (PSAs) were prepared via UV-irradiaton of an acrylic syrups with reactive diluent (functional diacrylate) and photoinitiator. The acrylic syrups were received via free radical bulk polymerization process (FRBP) and influence of radical photoinitiator ( $\alpha$-hydroxyketones, acylphosphine oxides or mixtures thereof) was investigated. It was revealed that the mixture of bisacylphosphine oxide (Omnirad 819) and $\alpha$-hydroxyketone (Omnirad 184) was the most effective in FRBP (the highest monomer conversion), but preferable features of acrylic syrups (viscosity and molecular weight of copolymers) and self-adhesive properties of PSAs (especially cohesion) was achieved due to $\alpha$-hydroxyketones using.
\end{abstract}

Keywords: bulk photopolymerization, acrylic syrup, radical photoinitiators, pressure-sensitive adhesives.

\section{Wpływ fotoinicjatorów na właściwości poliakrylanowych syropów i klejów samoprzylepnych}

Streszczenie: Z syropów akrylanowych oraz wielofunkcyjnego monomeru i fotoinicjatora rodnikowego otrzymano poliakrylanowe kleje samoprzylepne. Syropy akrylanowe uzyskano metodą fotopolimeryzacji $\mathrm{w}$ masie monomerów z zastosowaniem różnych fotoinicjatorów rodnikowych (z grupy $\alpha$-hydroksyketonów, tlenków acylofosfiny i ich mieszanin). Stwierdzono, że najbardziej efektywna w procesie fotopolimeryzacji jest mieszanina fotoinicjatorów: tlenku bisacylofosfiny (Omnirad 819) i $\alpha$-hydroksyketonu (Omnirad 184) (największa wartość konwersji monomerów), jednak większą lepkością oraz większymi ciężarami cząsteczkowymi cechowały się syropy akrylanowe z udziałem $\alpha$-hydroksyketonów (Omnirad 127 lub Omnirad 184), a uzyskane z nich kleje wykazywały lepsze cechy samoprzylepne, zwłaszcza kohezję.

Słowa kluczowe: fotopolimeryzacja w masie, akrylany, fotoinicjatory rodnikowe, kleje samoprzylepne.

The first article on photopolymerization initiated using the sun light appeared in 1845 [1]. However, photochemical reactions began to be used on a larger scale in the mid-twentieth century. Printing technology companies (Eastman Kodak and DuPont) significantly contributed to the development of this technology [2, 3]. In the 1990s, UV technology was expanding rapidly - in 1995 the global market of UV-cured systems has reached a billion dollars [4]. High reaction rate, lower energy costs or the possibility of solvent-free polymerization - these benefits allow considering the photopolymerization method as pro-ecological, willingly used in many industries and still intensively

\footnotetext{
1) West Pomeranian University of Technology in Szczecin, Faculty of Chemical Technology and Engineering, Pulaskiego 10, 70-322 Szczecin, Poland.

*) The part of article was presented at the Pomerania-Plast 2019 Conference, June 5-7, 2019, Międzyzdroje, Poland.

**) Author for correspondence:

agnieszka.kowalczyk@zut.edu.pl
}

developed by research centers [5, 6]. Currently, photopolymerization are encountered in various experimental conditions, for example, in film, gas phase, aerosol, multilayers, solid state, on surface, in ionic liquid or under magnetic field [7]. However, the most common photopolymerization method is film photopolymerization (radical or cationic), for example photopolymerization of acrylates, epoxides, vinyl ethers. This type of photopolymerization is mainly used for cross-linking of polymeric materials, such as: varnishes, hydrogels, dental fillings, printing inks and adhesives [8-13]. Photopolymerization in film is extremely effective, especially radical photopolymerization of multifunctional monomers and oligomers is very fast - in seconds, with the help of light, a viscous liquid turns into a solid. This process has been discussed in many publications [14-18]. On the other hand, the process of free radical bulk photopolymerization (FRBP) is relatively rarely mentioned [19-22]. FRBP process is a photopolymerization initiated by the decomposition of the photoinitiator into radicals, that occurs in a large volume of reagents with mixing. Finally prod- 
uct from FRBP is solution of polymer in unreacted monomers (called polymer syrup), less often a polymer. Received syrup, which is a solvent-free binder, only need to be mixed with additives (additional part of photoinitiator, multifunctional monomers or oligomers) to create a composition for coating materials (e.g. varnishes) or adhesives. After UV-crosslinking of such composition, finished product is achieved. Using this method, in the last few years, a group of scientists from Dankook University (Republic of Korea) obtained acrylate binders for optically clear pressure-sensitive adhesives (PSA's) [20, 23-27]. Researchers focused on obtaining optically clear adhesives using new monomers (tetrahydrofurfuryl acrylate, acryloyl morpholine, menthyl acrylate and derivatives of monosaccharides) and mainly in the presence of 1-hydroxy-cyclohexyl-phenyl-ketone as photoinitiator and 1-dodecanethiol as chain transfer agent. To the best of our knowledge, the available literature has no information on the effect of photoinitiators on the bulk photopolymerization process. However, numerous scientific studies are known about the effect of photoinitiators in film or solid state photopolymerization processes [28]. This paper presents preliminary results of our investigations on preparation of pressure-sensitive adhesives (PSAs) by means of free radical bulk photopolymerization process. The use of the FRBP process to obtain PSA tapes is particularly advantageous compared to conventional preparation methods, i.e. the time to obtain an adhesive binder is much shorter (only ca. $30 \mathrm{~min}$ in FRBP process and 6-8 h in free radical copolymerization of acrylate monomers in solvent) and no solvents are used, as is the case with conventional methods. The aim of this work was to determine the impact

I

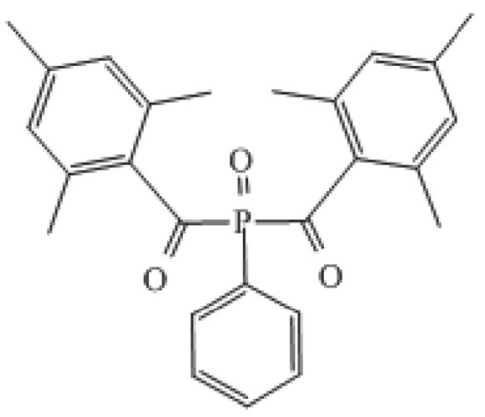

of selected radical photoinitiators (i.e. $\alpha$-hydroxyketones, acylphosphine oxides and mixtures thereof) on FRBP process of (meth)acrylate monomers, properties of obtained polymer syrups and self-adhesive properties of final product (i.e. acrylic pressure-sensitive adhesives). Additionally, the photopolymerization kinetics were monitored and polymerization rate and monomer conversion were determined.

\section{EXPERIMENTAL PART}

\section{Materials}

The following monomers were used for the preparation of polymer syrups using FRBP process: butyl acrylate (BA, Sigma Aldrich, Germany), butyl methacrylate (BMA, Sigma Aldrich, Germany), 2-hydroxyethyl acrylate (HEA, Sigma Aldrich, Germany). As the radical photoinitiators (PIs, IGM Resins, USA) were tested:

- acylphosphine oxides: bis(2,4,6-trimethylbenzoyl) phenylphosphine oxide [Omnirad 819, Formula (I)]; diphenyl(2,4,6-trimethylbenzoyl)phosphine oxide [Omnirad TPO, Formula (II)];

- $\alpha$-hydroxyketones: 2-hydroxy-1-\{4-[4-(2-hydroxy-2-methylpropionyl)benzyl]phenyl\}-2-methylpropan-1-one [Omnirad 127, Formula (III)], 1-hydroxy-cyclohexyl-phenyl-ketone [Omnirad 184, Formula (IV)].

The adhesive compositions consisted of: (i) obtained syrup; (ii) photoinitiator Irgacure 2022 - mixture of Irgacure 819 (80 wt \%) and Darocure 1173 (20 wt \%) (BASF, Germany) [Formula (V)]; (iii) 1,6-hexanediol diacrylate

II

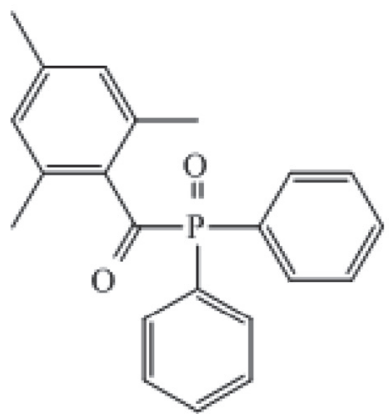<smiles>CC(C)(O)C(=O)c1ccc(Cc2ccc(C(=O)C(C)(C)O)cc2)cc1</smiles>

III<smiles>O=C(c1ccccc1)C1(O)CCCCC1</smiles><smiles>CC(C)(O)C(=O)c1ccccc1</smiles> 
(HDDA, BASF, Germany) as reactive diluent. The monomers and photoinitiators were applied without purification.

\section{Preparation of acrylic syrups}

The acrylic syrups (AS) were synthesized via free radical bulk photopolymerization (FRBP) of BA (3 mol), BMA ( $1 \mathrm{~mol})$ and HEA ( $1 \mathrm{~mol}$ ) and $1 \mathrm{mmol}$ of PIs. The FRBP process was carried out in a glass reactor $\left(250 \mathrm{~cm}^{3}\right)$ equipped with a mechanical stirrer (anchor) and thermocouple, in the presence of argon as an inert gas. A mixture of monomers (50 g) and PI were introduced into the reactor. Before starting the process, the reactor mixture was flushed with argon for $20 \mathrm{~min}$. Then the photopolymerization process was started. The source of ultraviolet radiation was a medium pressure mercury lamp (UVAHAND 250 GS, by Honle, intensity $10 \pm 2 \mathrm{~mW} / \mathrm{cm}^{2}$ ), placed perpendicular to the side wall of the reactor. The FRBP process was realized at room temperature for $30 \mathrm{~min}$.

\section{Preparation of PSAs}

The adhesive compositions for preparation one-sided adhesive tapes (PSAs) were compounded using the acrylic syrup (93 wt \%), photoinitiator Irgacure 2022 (4 wt \%) and reactive diluent HDDA ( $3 \mathrm{wt} \%$ ). The compositions were applied onto a polyester foil and UV-irradiated for $40 \mathrm{~s}$ (UV dose: $10 \mathrm{~J} / \mathrm{cm}^{2}$ ) using a medium pressure mercury lamp (Aktiprint-mini 18-2, type: UN50029, Technigraf $\mathrm{GmbH}$, Germany). The UV-exposition was controlled with a radiometer (Dynachem 500; Dynachem Corp., USA). Base weight and thickness of adhesive layers were $120 \mathrm{~g} / \mathrm{m}^{2}$ and $100 \mu \mathrm{m}$, respectively.

\section{Methods of testing}

\section{Characteristic of acrylic syrups}

The viscosity of AS (at $23^{\circ} \mathrm{C}$ ) was measured by means of DV-II Pro Extra viscometer (spindle \#7, 50 rpm; Brookfield, USA).

Monomer conversion after FRBP process was determined by nuclear magnetic resonance spectroscopy NMR
(Bruker DPX Avance III HD Spectrometer; 400MHz). The average molecular weights of obtained copolymers $\left(M_{n}\right.$ and $M_{w}$ ) and polydispersity $(\bigoplus)$ were performed by gel chromatography using polystyrene calibration in THF at $35^{\circ} \mathrm{C}$ at the Centre of Polymer and Carbon Materials of the Polish Academy of Sciences in Zabrze.

\section{Photopolymerization kinetics}

The kinetics of the photopolymerization process of monomer-PI systems (identical compositions to those involved in the FRBP) were tested using a differential scanning calorimeter with a UV attachment (DSC Q100, TA Instruments, USA; UV-light emitter Omnicure S2000; Excelitas Technologies, USA) at room temperature. Samples (5 mg) were irradiated with UV in the range 320-390 $\mathrm{nm}$ with an intensity of $250 \mathrm{~mW} / \mathrm{cm}^{2}$ in argon atmosphere. Polymerization rate $\left(R_{p^{\prime}} \% / \mathrm{s}\right)$ and conversion of double bonds $(p, \%)$ were calculated according to [29].

\section{PSAs properties}

Self-adhesive properties of the obtained PSAs were tested according to AFERA 4001 (adhesion to steel substrate), AFERA 4015 (tack) and AFERA 4012 (cohesion). These parameters were evaluated using three samples of each PSAs using a Zwick/Roell testing machine (Z010, ZwickRoell, Germany).

\section{RESULTS AND DISCUSSION}

The first stage of investigations was monitoring of photopolymerization process of acrylic monomers with PIs using photo-DSC method. Performing the photo-DSC tests was aimed at acquiring basic knowledge about the course of photopolymerization process of tested PIs with (met)acrylate monomers. However, it should be emphasized that the thin film photopolymerization (photo-DSC) process should not be compared with the FRBP process. Compositions of monomers and PIs were the same as for FRBP process (Table 1).

Figure 1 presents photopolymerization rate $R_{p}$ as function of irradation time in monomer mixtures. As can be

$\mathrm{T}$ a b l e 1. Compositions used to obtain acrylic syrups

\begin{tabular}{|c|c|c|c|c|c|}
\hline \multirow{2}{*}{$\begin{array}{l}\text { AS symbol/ } \\
\text { PSA }\end{array}$} & \multicolumn{2}{|c|}{$\begin{array}{l}\text { Photoinitiator } \\
\text { (1 mmol })\end{array}$} & \multicolumn{3}{|c|}{$\begin{array}{l}\text { Monomers } \\
\text { (molar ratio) }\end{array}$} \\
\hline & Type & Symbol & BA & HEA & BMA \\
\hline 819 & \multirow{2}{*}{ Acylphosphine oxide } & Omnirad 819 & \multirow{6}{*}{3} & \multirow{6}{*}{1} & \multirow{6}{*}{1} \\
\hline $\mathrm{TPO}$ & & Omnirad TPO & & & \\
\hline 127 & \multirow{2}{*}{$\alpha$-Hydroxyketone } & Omnirad 127 & & & \\
\hline 184 & & Omnirad 184 & & & \\
\hline $819 / 184^{*}$ & \multirow{2}{*}{$\begin{array}{c}\text { Acylphosphine } \\
\text { oxide/ } \alpha \text {-hydroxyketone }\end{array}$} & Omnirad 819/Omnirad 184 & & & \\
\hline $\mathrm{TPO} / 184^{*}$ & & Omnirad TPO/Omnirad 184 & & & \\
\hline
\end{tabular}

* $0.05 \mathrm{mmol}$ of acylphosphine oxide and $0.05 \mathrm{mmol}$ of $\alpha$-hydroxyketone. 


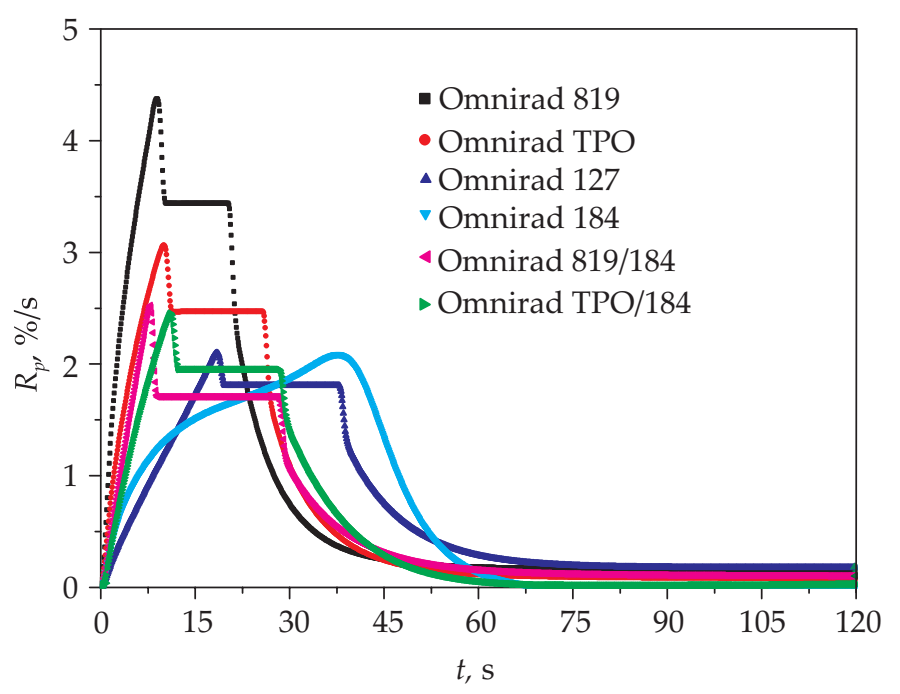

Fig. 1. Photopolymerization rate $R_{p}$ as function of irradation time in monomer mixtures (BA/BMA/HEA = $3: 1: 1 \mathrm{~mol}$ ) containing $1 \mathrm{mmol}$ of different PIs

observed, the highest value of $R_{p}$ was noted for sample with acylophospine oxide Omnirad 819 and the next was also acylophosphine oxide Omnirad TPO. Omnirad 819 is a bisacylphosphine oxide and generate four radicals per photoinitiator molecule, which means that one molecule of Omnirad 819 can initiate four chains (instead Omnirad TPO is monoacylphosphine oxide). For that reason, the $R_{p}$ for sample 819 was the highest. Nevertheless, in case of mixture with Omnirad 819 decrease in polymerization rate was the fastest. Probably, a large number of growing chains in thin films (in case of photo-DSC measurements, photopolymerization is carried out in relatively thin film), causes the increase of the viscosity of the system and inhibits the reaction. For this reason, full conversion of acrylic monomers was achieved after a relatively long time in comparison to other samples (after 170 s, Fig. 2). Similarly was in case of sample with Omnirad TPO, the full conversion of double bond was achieved after relatively long time (50 s). However, among other initiating systems, more reactive were mixtures of acylphosphine oxide with $\alpha$-hydroxyketon (819/184 and TPO/184), whereas the polymerization rate was the lower for system with $\alpha$-hydroxyketone Omnirad 184 (than Omnirad 127, Fig. 1). In this case, after $170 \mathrm{~s}$ of UV-exposure, the sample did not reach full conversion of double bond (ca. 80\%, Fig. 2). Among $\alpha$-hydroxyketones, bifunctional Omnirad 127

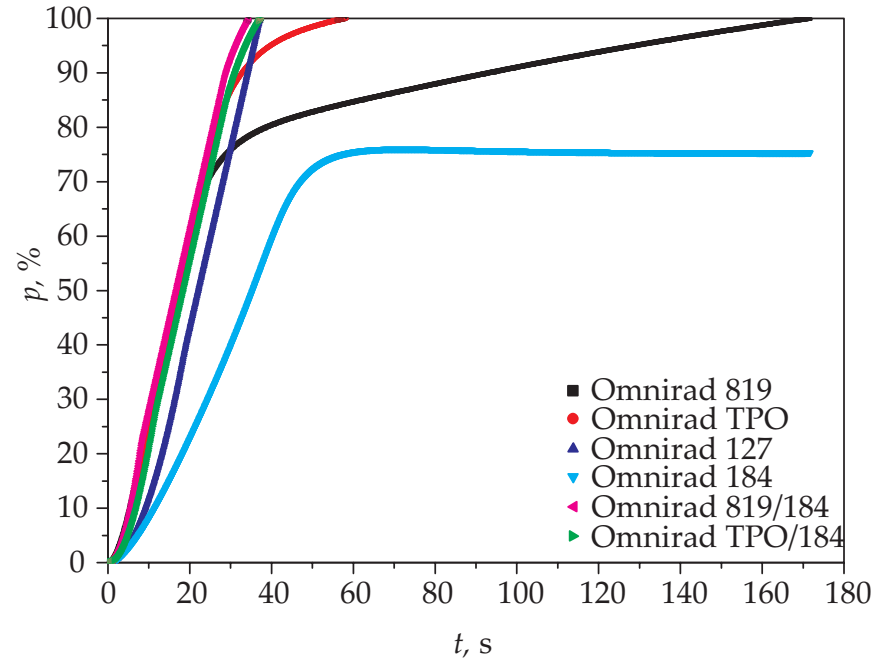

Fig. 2. Conversion of functional groups as function of irradation time in (meth)acrylate monomer mixtures (BA/BMA/HEA = $3: 1: 1 \mathrm{~mol})$ containing $1 \mathrm{mmol}$ of different photoinitiators

showed higher reactivity. However, the fastest full monomer conversion was achieved in mixed systems $(26 \mathrm{~s}$ for sample 819/184 and $30 \mathrm{~s}$ for TPO/184). Interestingly, photopolymerization process for all compositions was characterized by a short course (6-10 seconds) with a constant reaction rate. Only for sample with Omnirad 184, the kinetic curve was slightly different. Unpublished results of the authors indicate that the effect of constant reaction rate results from monomer mixture composition. In conclusion, studied using photo-DSC method have shown that the highest maximum polymerization rate characterized systems with acylphosphine oxide than $\alpha$-hydoxyketones and mixtures of PIs (819/184 and TPO/184) achieved an intermediate results. Nevertheless, samples with mixtures of PIs were the fastest to obtain full monomer conversion.

The main stage of work was the preparation of AS via FRBP process in glass reactor. The compositions to FRBP process, i.e. acrylic monomers with photoinitiator(s) were shown in Table 1.

Obtained AS were characterized according to the basic properties affecting the coating process and properties of the final product, i.e. monomer conversion, molecular weights and viscosity. The results were presented in Table 2.

Acrylic syrup 819/184 characterized the highest monomer conversion (65.3\%), which correlates with photo-DSC

T a b 1 e 2. Physicochemical properties of obtained acrylic syrups

\begin{tabular}{c|c|c|c|c|c}
\hline AS symbol & $\begin{array}{c}\text { Monomer } \\
\text { conversion } \%\end{array}$ & $\begin{array}{c}M_{n} \\
\mathrm{~g} / \mathrm{mol}\end{array}$ & $\begin{array}{c}M_{w} \\
\mathrm{~g} / \mathrm{mol}\end{array}$ & $\begin{array}{c}\eta \\
\mathrm{Pa} \cdot \mathrm{s}\end{array}$ \\
\hline 819 & 60.6 & 23000 & 110800 & 4.82 & 11 \\
TPO & 32.0 & 26500 & 129100 & 4.88 & 1 \\
127 & 52.8 & 84700 & 231500 & 2.73 & 22 \\
184 & 45.7 & 94000 & 342700 & 3.64 & 3.5 \\
$819 / 184$ & 65.3 & 35800 & 160400 & 4.48 & 3.11 \\
TPO/184 & 36.2 & 41600 & 171200 & & 3 \\
\hline
\end{tabular}


test results (sample achieved the full conversion of monomers in the shortest time). The high reactivity of mixed system $819 / 184$ can be explained by generation of six various radicals (four from Omnirad 819 and two from Omnirad 184). It caused the relatively high photopolymerization rate. It is worth mentioning that, FRBP process is fundamentally different from film photopolymerization (like in case of photo-DSC) in that it takes place in a large volume and the sample is mechanically mixed during the process. For this reason, radicals and macro-radicals have more possibilities to react, and the effect of the increase in viscosity is no longer as strong. Sample 819/184 characterized also the highest viscosity $(32 \mathrm{~Pa} \cdot \mathrm{s})$ and one of the largest polydispersity (4.48). Probably, it is caused by effect of six different radials in system. Generally, the viscosity of ASs increased with increase of monomer conversion. The lowest value of viscosity $(1 \mathrm{~Pa} \cdot \mathrm{s})$ was for AS with TPO and monomer conversion reached only $32 \%$. Also sample TPO/184 exhibited low values of viscosity and monomer conversion ( $3 \mathrm{~Pa} \cdot \mathrm{s}$ and $36.2 \%$, respectively). It is interestingly, that ASs obtained using acylphosphine oxide were so different. AS 819 achieved very high monomer conversion $(60.6 \%)$ and relatively high viscosity $(11 \mathrm{~Pa} \cdot \mathrm{s})$, whereas AS with TPO $-32 \%$ of monomer conversion and the lowest viscosity $(1 \mathrm{~Pa} \cdot \mathrm{s})$. It is known from the literature that Omnirad 819 strongly absorbs UV radiation than Omnirad TPO and is twice as effective. NMR analysis of acrylic syrups (i.e. monomer conversion) showed differences between film photopolymerization (photo-DSC results) and FRBP process. In film photopolymerization, Omnirad TPO was more effective than Omnirad 819 (time to achieved the full conversion of monomers was short in comparison to sample with Omnirad 819, Fig. 2). Hence it can be concluded that until now photoinitiators dedicated to photopolymerization processes occurring in a thin film are not suitable for processes occurring in large volumes. Moreover, it was stated that monomer conversion was improved in case of systems with two kind of PIs (acylphosphine oxide and $\alpha$-hydroxyketone). Nevertheless, it should be noted that ASs with $\alpha$-hydroxyketones Omnirad 127 and Omnirad 184 characterized by relatively high monomer conversion (52.8 and 45.7\%, respectively) and high viscosity (22 and $13.5 \mathrm{~Pa} \cdot \mathrm{s}$, respectively). In the case of these photoinitiators, the principle that more functional photoinitiator is more effective (Omirad 127 is bifunctional particle) was confirmed. Additionally, it should be emphasized that copolymers obtained using $\alpha$-hydroxyketones characterized by significantly higher values of $M_{n}(84700$ and $9400 \mathrm{~g} / \mathrm{mol})$ and $M_{w}(231500$ and $342700 \mathrm{~g} / \mathrm{mol})$ and lowest polydispersity (2.73 for Omnirad 127 and 3.64 for Omnirad 184) than other copolymers. Significantly low values of $M_{n}$ and $M_{w}$ were noticed for AS with acylphosphine oxides (819 and TPO). To sum up, the physicochemical characteristic of obtained acrylic syrups exhibited that $\alpha$-hydroxyketones Omnirad 127 and Omnirad 184 were more suitable for FRBP process of acrylic monomers because give AS with relatively high monomer conversion (ca. 50\%), viscosity

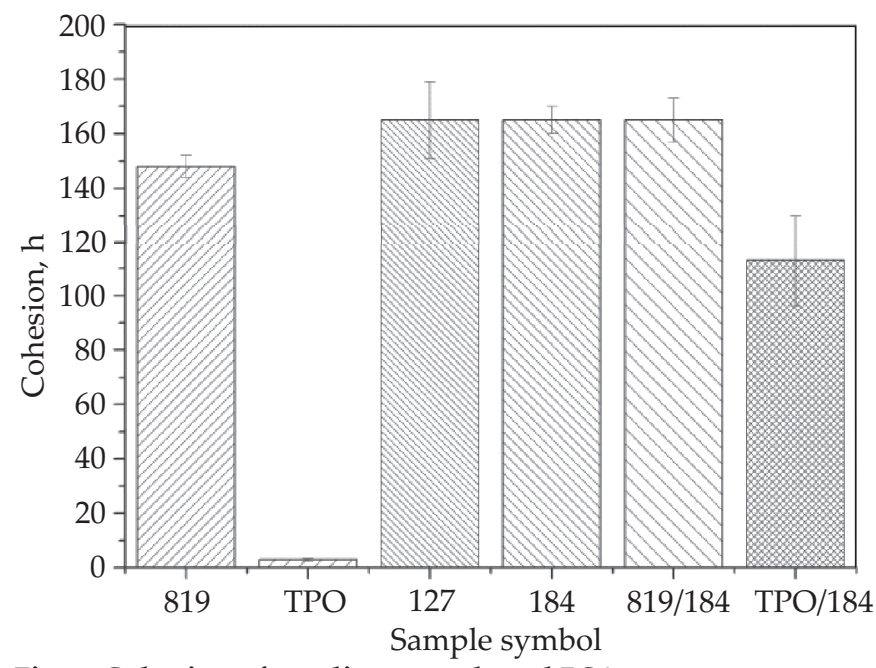

Fig. 3. Cohesion of acrylic syrups based PSAs

and molecular weight $\left(M_{n}\right.$ and $\left.M_{w}\right)$ and comparatively low polydispersity.

Regarding the self-adhesives properties of PSAs based on AS (cohesion, adhesion to steel and tack), it should be noted that all PSAs, reached cohesion values more than desirable (i.e. 72 h), except PSA TPO (only 3 h), Fig. 3.

The highest value of cohesion exhibited PSAs based on ASs with acylphosphine oxides (Omnirad 127 and Omnirad 184) and one of the mixed systems (819/184), the cohesion values were more than $165 \mathrm{~h}$. Additionally, very good result of cohesion was for PSA 819 (148 h). It is also worth noting that the samples obtained from syrups with higher monomer conversion and higher $M_{n}$ and $M_{w}$ were characterized by higher cohesion. Samples PSAs TPO and PSA TPO/184 were the weakest in this respect. It can also be caused by the fact that the amount of photoinitiator (Irgacure 2022) for UV-crosslinking of these systems was insufficient (ca. 60\% of unreacted monomers in adhesive composition). In the case of adhesion to steel (Fig. 4) and tack (Fig. 5) of tested PSAs, the highest values of these features were noted for PSA TPO (adhesion - $12 \mathrm{~N} / 25 \mathrm{~mm}$ and $27 \mathrm{~N}$ - tack). Generally, for PSA characteristic is that the

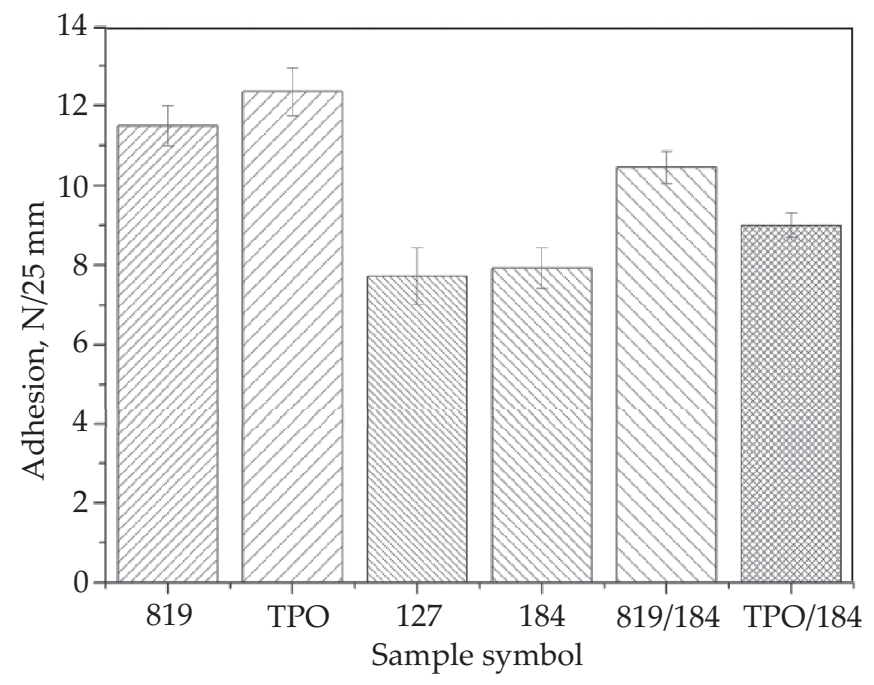

Fig. 4. Adhesion to steel of acrylic syrups based PSAs 


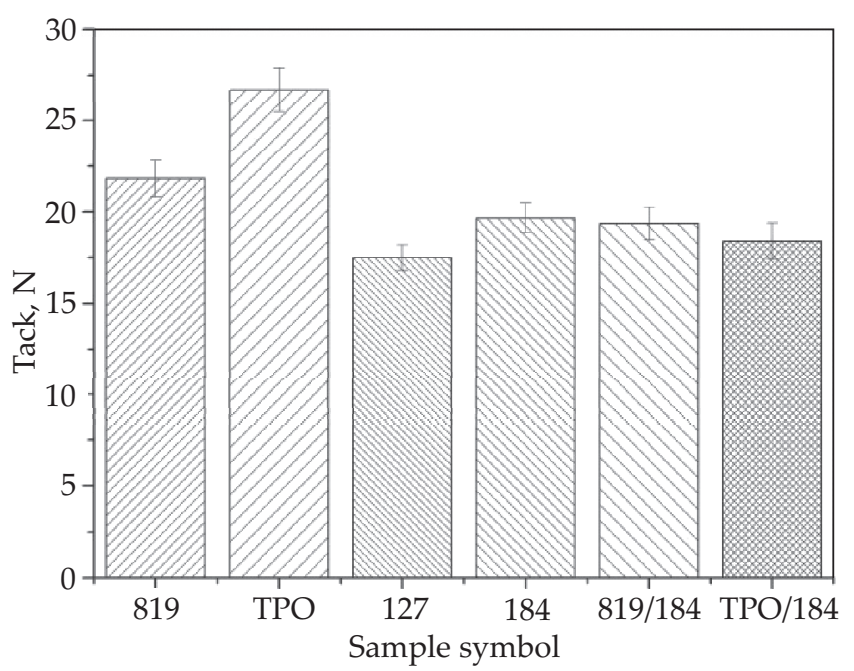

Fig. 5. Tack od acrylic syrups based PSAs

adhesive films with a low degree of crosslinking, low molecular weights of polymers from which they are formed are exhibit low cohesion and high adhesion. Despite the fact that samples PSA 127 and PSA 184 had the lowest adhesion (7.7 N/25 mm and $7.9 \mathrm{~N} / 25 \mathrm{~mm}$, respectively) and tack (17.5 N and $19.6 \mathrm{~N}$, respectively), they exhibited very high cohesion ( $165 \mathrm{~h}$ ) so the obtained result of self-adhesive features was advantageous. Nevertheless, the sample with the mixture of photoinitiators (PSA 819/184) turned out to be the best self-adhesive features $(10.4 \mathrm{~N} / 25 \mathrm{~mm}-$ adhesion, $19.3 \mathrm{~N}$ - tack and $165 \mathrm{~h}$ - cohesion).

\section{CONCLUSIONS}

The influence of $\alpha$-hydroxyketones, acylphosphine oxides and mixtures thereof on photopolymerization kinetics and features of acrylic syrups and self-adhesive properties of the pressure-sensitive adhesives was investigated. Thus, the following conclusion can be drawn:

- Mixtures of acylphosphine oxides and $\alpha$-hydroxyketones (i.e. Omnirad 819/Omnirad 184 and Omnirad TPO/Omnirad 184) more effectively initiate the film photopolymerization process (photo-DSC results) of (meth)acrylate monomers, probably it is connected with absorption characteristics of the photoinitiators mixtures with monomers. Full conversion of monomers can be reached after $26 \mathrm{~s}$ and $30 \mathrm{~s}$, respectively. Although, the highest maximum $R_{p}$ exhibited acylphosphine oxides (Omnirad 819) the time to full monomer conversion was almost the longest (170 s). Generally acylphosphine oxides proved less effective in the film photopolymerization process of (meth)acrylates.

- Mixture of Omnirad 819/Omnirad 184 and Omnirad 819 were more effective in the FRBP process (monomer conversion in excess of $60 \%$ ), nonetheless $\alpha$-hydroxyketones provided acrylic syrups with higher $M_{n^{\prime}} M_{w}$ and viscosity and less polydispersity while maintaining the high level of monomer conversion (ca. 50\%).

- The viscosity and monomer conversion in acrylic syrups and $M_{n}$ and $M_{w}$ of copolymers have a major impact on the self-adhesive properties of PSAs. Preferable results were obtained for those with higher $M_{n^{\prime}} M_{w}$ and high viscosity and monomer conversion.

Free radical bulk photopolymerization process is very fast and comfortable method of obtaining pressure-sensitive adhesives, however choosing a radical photoinitiator is crucial.

\section{REFERENCES}

[1] Scheirs J.: “Modern Styrenic Polymers: Polystyrene and Styrenic Copolymers" (Eds. Scheirs J., Priddy D.), John Wiley \& Sons Ltd., Chichester 2003, p. 4.

[2] US Pat. 2610120 (1952).

[3] US Pat. 2760863 (1956).

[4] Scranton A.B.: "Photopolymerization: Fundamentals and Application" (Eds. Scranton A.B., Bowman C.N., Peiffer R.W.), ACS Symposium Series, American Chemical Society, Washington 1997, ix.

[5] Decker C.: Progress in Polymer Science 1996, 21, 593. https://doi.org/10.1016/0079-6700(95)00027-5

[6] Yagci Y., Jockusch S., Turro N.J.: Macromolecules 2010, $43,6245$. https://doi.org/10.1021/ma1007545

[7] Fouassier J.P., Lalevée J.: "Photoinitiators for Polymer Synthesis", Wiley-VCH Verlag \& Co. KGaA, Weinheim 2012, p. 21.

[8] Wang Z., Liang H., Yang H. et al.: Progress in Organic Coatings 2019, 137, 105282. https://doi.org/10.1016/j.porgcoat.2019.105282

[9] Lorusso E., Ali W., Hildebrandt M. et al.: Polymers 2019, $11(8), 1329$. https://doi.org/10.3390/polym11081329

[10] Cadenaro M., Maravic T., Comba A. et al.: Dental Materials 2019, 35, e1. https://doi.org/10.1016/j.dental.2018.11.012

[11] Wagner A., Mühlberger M., Paulik C.: Journal of Applied Polymer Science 2019, 136 (29), 47789. https://doi.org/10.1002/app.47789

[12] Lee J.H., Myung M.H., Baek M.J. et al.: Polymer Testing 2019, 76, 305. https://doi.org/10.1016/j.polymertesting.2019.03.033

[13] Mozelewska K., Bednarczyk P., Czech Z.: Przemyst Chemiczny 2018, 97, 1559. https://doi.org/10.15199/62.2018.9.34

[14] Andrzejewska E.: Progress in Polymer Science 2001, 26, 605. https://doi.org/10.1016/S0079-6700(01)00004-1

[15] Garra P., Dietlin C., Morlet-Savary F. et al.: Polymer Chemistry 2017, 8, 7088. https://doi.org/10.1039/C7PY01778B

[16] Fouassier J.P., Lalevée J.: "Photoinitiators for Polymer Synthesis: Scope, Reactivity and Efficiency", WileyVCH, Weinheim 2012, p. 21.

[17] Czech Z., Urbala M.: Polimery 2007, 52, 438. https://doi.org/10.14314/polimery.2007.438

[18] Khudyakov I.V.: Progress in Organic Coatings 2018, 121, 151. 
https://doi.org/10.1016/j.porgcoat.2018.04.030

[19] US Pat. 4141806 (1979).

[20] Baek S.S., Jang S.J., Hwang S.H.: International Journal of Adhesion and Adhesives 2016, 64, 72. https://doi.org/10.1016/j.ijadhadh.2015.10.005

[21] Bednarczyk P., Gziut K., Kowalczyk A.: Przemyst Chemiczny 2018, 97, 1000.

https://doi.org/10.15199/62.2018.11.11

[22] PL Pat. Appl. 429645 (2019).

[23] Baek S.S., Jang S.J., Lee S.W., Hwank S.H.: Polymer Korea 2014, 38 (5), 682. https://doi.org/10.7317/pk.2014.38.5.682

[24] Baek S.S., Hwang S.H.: Polymer Bulletin 2016, 73 (3), 687.

https://doi.org/10.1007/s00289-015-1510-5
[25] Baek S.S., Hwang S.H.: International Journal of Adhesion and Adhesives 2016, 70, 110. https://doi.org/10.1016/j.ijadhadh.2016.06.002

[26] Baek S.S., Jang S.J., Hwang S.H.: Journal of Industrial and Engineering Chemistry 2017, 53 (25), 429. https://doi.org/10.1016/j.jiec.2017.05.017

[27] Kim J.S., Shim G.S., Baek D., Back J.H.: Express Polymer Letters 2019, 13 (9), 794. https://doi.org/10.3144/expresspolymlett.2019.68

[28] Green W.A.: "Industrial Photoinitiators. A Technical Guide", CRC Press Taylor and Francis Group, Boca Raton 2010, pp. 75-93.

[29] Pączkowski J.: „Fotochemia polimerów. Teoria i zastosowanie", Wydawnictwo Uniwersytetu Mikołaja Kopernika, Toruń 2003, p. 115.

Received 18 X 2019. 